\title{
Sleep and Sleep Disorders in Chronic Obstructive Pulmonary Disease
}

\author{
Nancy Collop \\ Johns Hopkins University, Baltimore, Md., USA
}

\section{Key Words}

Chronic obstructive pulmonary disease $\cdot$ Hypoventilation . Insomnia $\cdot$ Pulmonary function · Sleep disturbances

\begin{abstract}
Chronic obstructive pulmonary disease (COPD) is one of the leading causes of death in the US. Numerous studies have demonstrated that sleep disturbances are common in COPD patients, with more prominent complaints in patients with more severe disease and with increasing age. Sleep disturbances may occur due to the effects of breathing abnormalities on sleep and sleep disruption. However, other etiologies may include the medications used to treat COPD, concomitant anxiety and depression, and the presence of comorbid sleep disorders. The respiratory disturbances that occur in these patients during sleep have been evaluated by examining sleep-related oxygen desaturation, reduction in pulmonary function during sleep, and development of hypoventilation during rapid eye movement sleep. Treatment includes use of nocturnal oxygen therapy, noninvasive positive pressure ventilation, and long-acting medications. There has been little study on improving sleep quality beyond treating the respiratory disease, despite the fact that numerous studies show poor sleep quality, a high prevalence of insomnia, and tolerability of newer hypnotic agents in the setting of COPD. This article defines the scope of sleep problems in the setting of COPD, reviews the impact of sleep on ventilation, explores the role of obstructive sleep apnea in the setting of COPD, and reviews therapeutic options.
\end{abstract}

Copyright $\odot 2009$ S. Karger AG, Basel

\section{Introduction}

Until the 1950s, sleep was considered to be a single state of rest. In 1953, however, electroencephalographic (EEG) recordings revealed that sleep actually occurs in stages that differ as much from each other as sleep differs from wakefulness (fig. 1). The transitional stage from wake, called stage 1 sleep (N1), is followed by stage 2 sleep (N2), with decreased frequency of EEG waves and an increase in their amplitude, together with spike clusters referred to as sleep spindles and slow oscillation called $\mathrm{K}$ complexes. Stage 3 and 4 sleep (N3) is deep sleep, and the amplitude of low-frequency waves continues to increase while the number of spindles decreases (slow-wave sleep). Collectively, these sleep stages are termed non-rapid eye movement (NREM) sleep; the sequence from stage 1 to stage 4 is typically about $1 \mathrm{~h}$ [1].

Following a period of slow-wave sleep, however, EEG recordings show that the NREM stages of sleep transform to rapid eye movement (REM) sleep, a very active physiological state profoundly different from NREM sleep (table 1). After about $10 \mathrm{~min}$ in REM sleep, the brain typically cycles back through the NREM sleep stages [1]. With each cycle, the REM period becomes progressively longer. As people age, the time spent in N3 sleep decreases, but the percentage of time spent in REM sleep remains unchanged [2]. These sleep phases affect respiration in different ways.

\section{KARGER}

Fax +4161306 1234

E-Mail karger@karger.ch

www.karger.com
(C) 2009 S. Karger AG, Basel

0025-7931/10/0801-0078\$26.00/0

Accessible online at:

www.karger.com/res
Nancy Collop, MD, FCCP

Johns Hopkins University

1830 East Monument Street

Baltimore, MD 21205-2195 (USA)

Tel. +1 443287 3313, Fax +1 443287 3312, E-Mail ncollop1@jhmi.edu 
Fig. 1. Physiological changes in a male volunteer during the various sleep states in a typical 8-hour period of sleep. a The duration of REM sleep increases from $10 \mathrm{~min}$ in the first cycle to up to $50 \mathrm{~min}$ in the final cycle; note that slow-wave (stage 4) sleep is attained only in the first two cycles. b The upper panels show the electrooculogram (EOG) and the lower panels show changes in various muscular and autonomic functions. Movement of neck muscles was measured using an electromyogram (EMG). Other than the few slow eye movements approaching stage 1 sleep, all other eye movements evident in the EOG occur in REM sleep. The greatest EMG activity occurs during the onset of sleep and just prior to awakening. The heart rate (beats per minute) and respiration (breaths per minute) slow in NREM sleep, but increase almost to the waking levels in REM sleep. Finally, penile erection occurs only during REM sleep (after Schmidt et al., 1983; source: Purves et al. [1], reproduced with permission).

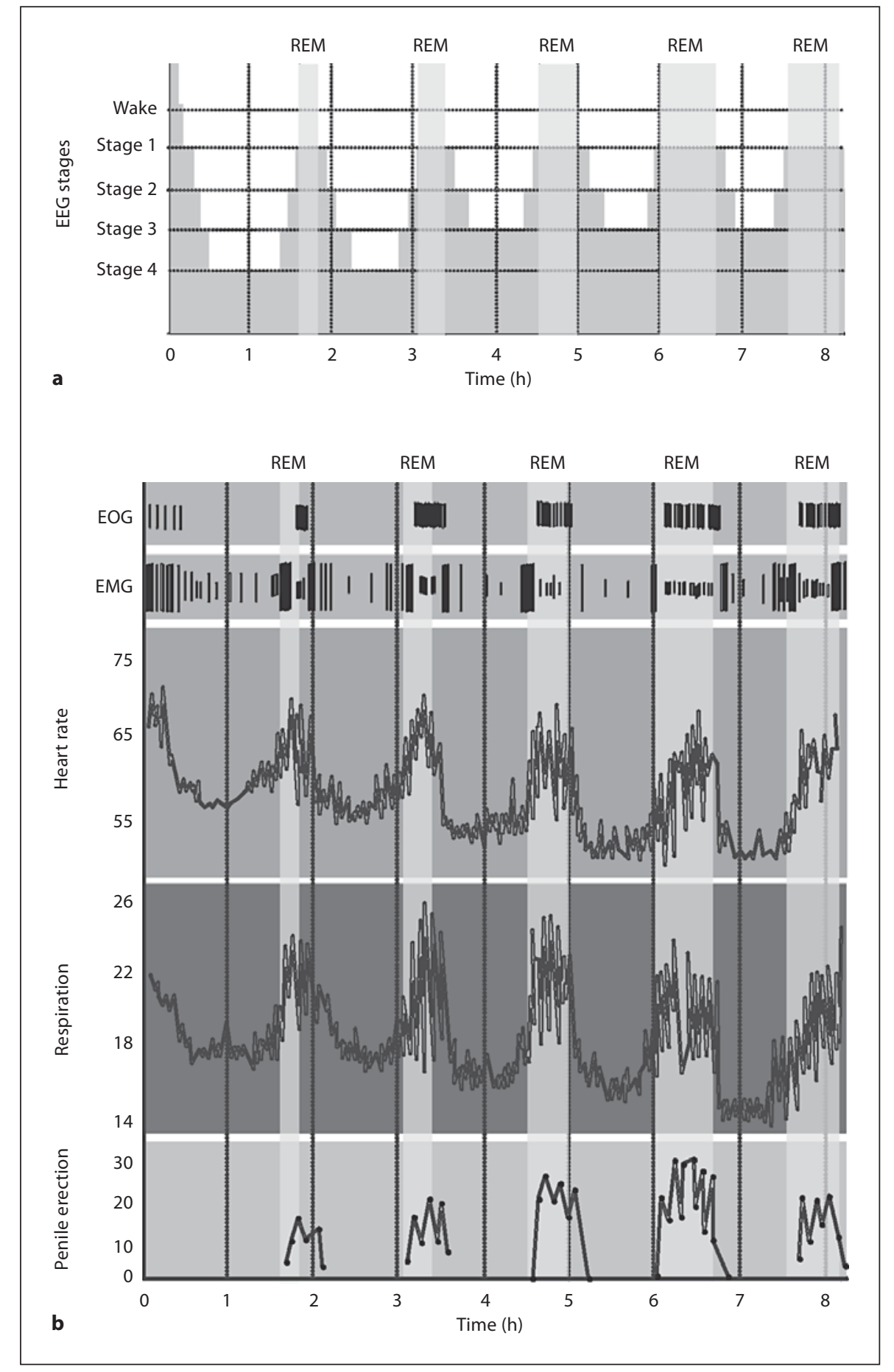

\section{Impact of Sleep on Normal Ventilation}

As shown in figure 2, at sleep onset, ventilation decreases due to multiple contributing factors. The reticular activating system and metabolic rate decrease, chemo- sensitivity is reduced, and upper airway resistance increases with sleep onset. The resulting decrease in ventilation results in an increase in the partial pressure of carbon dioxide in the arterial blood $\left(\mathrm{PaCO}_{2}\right)$ despite the decrease in metabolic rate, and a decrease in the partial 
Fig. 2. In normal individuals experiencing a typical sleep cycle, decreases in reticular activating system (RAS) activity, metabolic rate, and responsiveness to arterial $\mathrm{PaO}_{2}$ and $\mathrm{PaCO}_{2}$ along with increased airway resistance lead to decreased ventilation and subsequent changes in arterial blood gases during sleep (source: Mohsenin [2], p 110, fig. 1 , reproduced with permission).

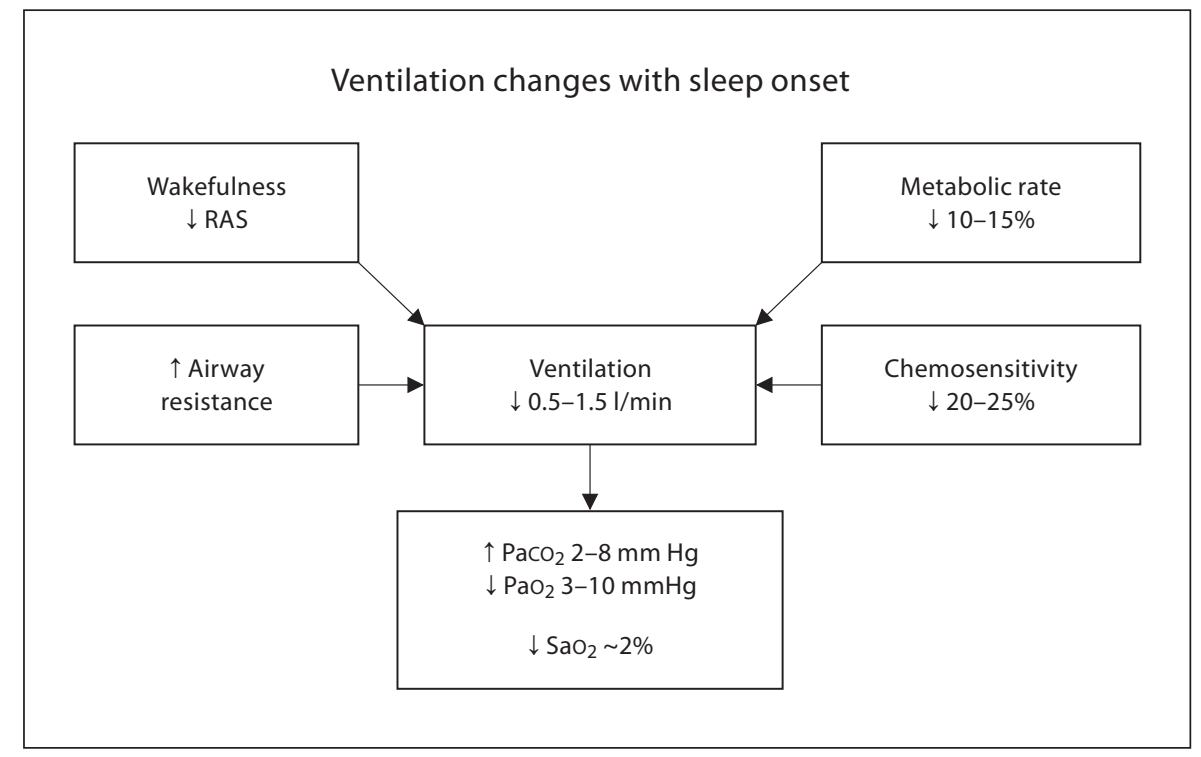

Table 1. REM versus NREM sleep

\begin{tabular}{lll}
\hline Physiologic variable & NREM & REM \\
\hline Heart rate & regular & irregular \\
Respiratory rate & regular & irregular \\
Blood pressure & regular & variable \\
Skeletal muscle tone & reduced & absent \\
Brain $\mathrm{O}_{2}$ consumption & reduced & increased \\
Ventilatory response & reduced & reduced \\
Temperature & normal & poikilothermic \\
Sexual changes & rare & frequent \\
\hline
\end{tabular}

Adapted from Parmeggiani [76].

pressure of oxygen $\left(\mathrm{PaO}_{2}\right)$ levels despite respiration remaining stable with only rare apneas. To the contrary, REM sleep is characterized by significant breath-tobreath variability, increased mean respiratory frequency, marked reductions in ventilation with bursts of eye movements, and further decreases in the carbon dioxide response [2].

An early study of ventilation during sleep in normal subjects [3] revealed a greater decrease in ventilation in REM sleep compared to wakefulness. These falls in ventilation resulted almost entirely from changes in tidal volume (VT) and mean inspiratory flow (VT/TI) and not from changes in timing. The fractional abdominal contribution to ventilation fell during slow-wave sleep but returned to awake levels during REM sleep, suggesting that the actual rib-cage and abdominal contributions to ventilation were equally reduced during REM sleep compared to awake periods. Despite a decrease in overall ventilation during slow-wave sleep, the ribcage contribution to ventilation was actually higher. Snoring profoundly affected the proportions of rib-cage and abdominal contributions [3]. Decreases in minute ventilation during slow-wave sleep compared to wakefulness resulted from a change in tidal volume and not from changes in respiratory frequency which remained relatively consistent during sleep.

Figure 3 illustrates the effect of carbon dioxide levels on ventilation during sleep/wake stages. It shows that during REM sleep, there is less sensitivity to hypercapnia as compared to NREM stages and wakefulness [4].

\section{Impact of Sleep on Ventilation in Patients with Chronic Obstructive Pulmonary Disease}

Two distinct clinical patterns are seen in patients with chronic obstructive pulmonary disease (COPD). Chronic bronchitic patients (type B) are hypoxemic, retain $\mathrm{CO}_{2}$, have cor pulmonale and a chronic productive cough, and are commonly overweight. Emphysematous patients (type A) have relatively normal arterial blood gases, are thin and hyperinflated, and have a significantly decreased lung diffusion capacity for carbon monoxide. Both type A and type B patients typically have characteristic fea- 


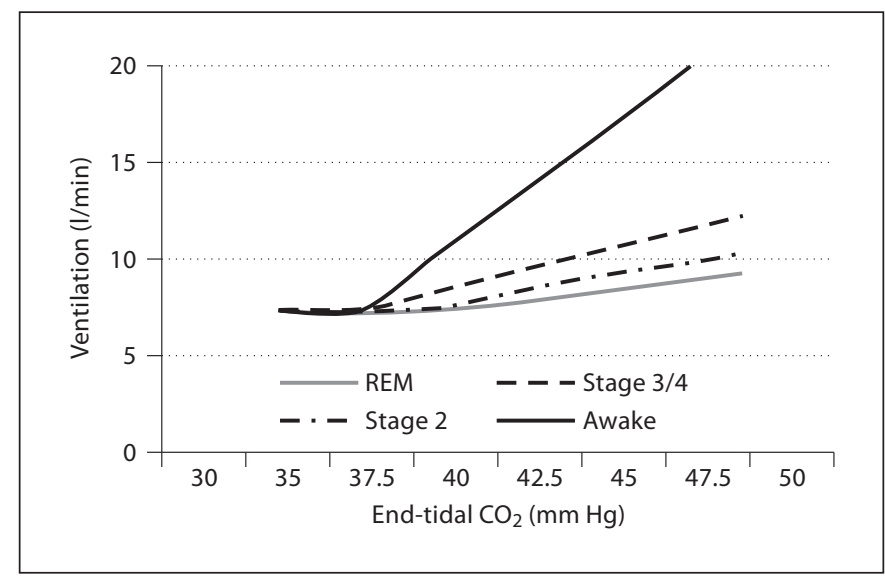

Fig. 3. The effect of increasing $\mathrm{CO}_{2}$ levels on ventilation during wakefulness as compared to different sleep stages. During wakefulness there is a robust response to $\mathrm{CO}_{2}$ levels manifested by a rapid escalation in minute ventilation; however with sleep, the response to $\mathrm{CO}_{2}$ levels is reduced with the lowest responsiveness occurring during REM sleep (source: Collop et al. [74], reproduced with permission).

tures of chronic bronchitis and emphysema [5]. When 4 type $B$ and 6 type A patients were monitored during sleep to determine the incidence of abnormal breathing and oxygen desaturation in each group [5], notable differences were observed. Type B patients demonstrated severe sleep hypoxemia attributed to lower baseline oxygen saturations during sleep, and also due to severe episodic desaturation caused by an altered breathing pattern. Conversely, type A patients experienced only minor reductions in oxygen saturation during sleep [5]. Thehypoxemia reported in this study has been well documented elsewhere as occurring primarily during REM sleep [5-9] and potentially causing sustained pulmonary hypertension $[10,11]$. Overall, patients who are most hypoxemic when awake experience the most severe hypoxemia when asleep [12]. COPD patients may spend more than $30 \%$ of sleep time with low oxygen levels [13].

\section{Mechanisms of Nocturnal Deoxygenation}

Various mechanisms are thought to contribute to the nocturnal hypoxemia that occurs with COPD. Table 2 lists potential mechanisms. First, it is intuitively apparent that because COPD patients have a lower oxygen saturation during wakefulness, the normal ventilation changes that occur with sleep exacerbate this preexisting state to
Table 2. Proposed mechanisms for NOD

Start lower on oxyhemoglobin dissociation curve

Reduced chemoresponsiveness (less likely to arouse from sleep due to hypoxia or hypercapnia)

More reliance on accessory muscles during wakefulness -

REM-related atonia causes loss of the activity of these muscles Greater reduction in functional residual capacity with sleep onset Increased upper airway resistance

Increased ventilation-perfusion mismatch

the point of severity. Second, hypoventilation that occurs at sleep onset is in part due to a reduction in muscle tone causing increased upper airway resistance. In addition, during REM sleep there is further reduction in skeletal muscle tone. This atonia is thought to be both more profound in COPD patients during REM sleep and the result of an increased reliance on intercostal and accessory muscles of inspiration during waking hours, which causes profound effects on ventilation when these muscles become atonic during REM [14]. This REM-related hypoventilation has also been observed in a wide variety of other lung, neuromuscular and skeletal disorders, due to a fall in tidal volume related to a loss of accessory muscle use [15]. Third, because COPD patients have blunted chemoresponsiveness, they arouse less frequently during sleep, and breathing patterns do not have an opportunity to normalize to the waking state, thus oxygen saturation is impaired for extended periods of time [16]. Fourth, ventilation-perfusion mismatch is thought to occur as studies have shown that there are greater changes in oxygen levels than in carbon dioxide levels during REM sleep [17-19]. This may be in part due to reduction in functional residual capacity, which decreases approximately $10 \%$ when an individual is in the recumbent position, with further evidence suggesting that patients with COPD may experience even more profound decreases [20]. The combined effect of these mechanisms is a persistent and dramatic decrease in oxygen saturation throughout the REM cycle [21, 22].

\section{Diagnostic Criteria and Predictors}

Sleep-related hypoventilation/hypoxemia due to COPD falls under the ICD-9 code 780.57. Diagnostic criteria appear rather arbitrary, but have been established as an oxygen saturation of hemoglobin $\left(\mathrm{SaO}_{2}\right)<90 \%$ for $>5$ min (nadir $85 \%$ ) or $>30 \%$ of total sleep time (TST) at $\mathrm{SaO}_{2}$ 
$<90 \%)$. In the unlikely event that it is possible to obtain a blood gas measure during sleep, a diagnostic criterion is a $\mathrm{PaCO}_{2}$ disproportionately increased relative to wakefulness $(>45 \mathrm{~mm} \mathrm{Hg}$ ). Nocturnal oxygen desaturation (NOD) has been associated with a variety of medical problems, including episodic pulmonary hypertension. Rodent experiments have shown that when $\mathrm{PaO}_{2}$ is reduced intermittently during sleep, the rodents develop right ventricular hypertrophy $[23,24]$. Other conditions indirectly associated with NOD include increased arrhythmias, polycythemia, and increased mortality [25]. NOD, however, is not associated with differences in quality of life, sleep quality, or daytime function [26]. Interestingly, diagnosing NOD may require more than one nocturnal oximetry as large night-to-night variations have been noted [27].

In a subset analysis of the Sleep Heart Health Study [28], data from 1,132 participants with mild COPD were reviewed to determine predictors of oxyhemoglobin desaturation during sleep. After adjusting for confounding factors, the odds ratios for experiencing $>5 \%$ of TST with oxyhemoglobin saturation $\left(\mathrm{SpO}_{2}\right)<90 \%$ were calculated across a range of values measuring the forced expiratory volume in the 1st s and forced vital capacity (FVC). In the absence of sleep apnea, the adjusted odds ratio for nocturnal oxyhemoglobin desaturation increased at levels of $\mathrm{FEV}_{1} / \mathrm{FVC}$ below $65 \%$. In participants with an $\mathrm{FEV}_{1} / \mathrm{FVC}$ of $60-65 \%$, the adjusted odds ratio for desaturation to $<90 \%$ for $>5 \%$ TST was 1.92 (confidence interval: $1.1-$ 3.34). The adjusted odds ratio conferred by an $\mathrm{FEV}_{1} / \mathrm{FVC}$ $<60 \%$ was 3.36 (confidence interval: 1.98-5.7) [28]. Thus, quite low levels of $\mathrm{FEV}_{1} / \mathrm{FVC}$ were needed for a significant association with NOD, suggesting that patients with more serious COPD are more likely to experience this problem. Although these studies have examined physical endpoints, other opportunities for research include sleep quality, neurocognitive function, memory, and other comorbidities [29].

A number of NOD predictors have been studied. Lower pulmonary function test results $\left(\mathrm{FEV}_{1} / \mathrm{FVC}<60 \%\right)$ have been associated with NOD [30], but this finding has not been found in other studies. Unlike patients with cystic fibrosis, those with COPD who experience exerciserelated desaturation do not necessarily also experience NOD [31]. Earlier studies suggested inconsistent results for an association between NOD and awake $\mathrm{SaO}_{2}, \mathrm{PaO}_{2}$, or $\mathrm{PCO}_{2}[12,32]$. However, more current studies do suggest that NOD is more likely in patients with COPD when daytime $\mathrm{SaO}_{2} \leq 93 \%$, and unlikely when daytime $\mathrm{SaO}_{2}$ $\geq 95 \%[31,33,34]$.

\section{Sleep-Disordered Breathing in COPD: 'Overlap Syndrome'}

In patients with COPD, sleep apnea is not uncommon and can further exacerbate gas exchange during sleep. Known as the overlap syndrome [35], this association has been reported in $11 \%$ of 265 patients with obstructive airway disease referred to a sleep laboratory, most of whom were older males. However, the true prevalence of this syndrome is unknown [36]. These patients demonstrated lower $\mathrm{PaO}_{2}$ and higher $\mathrm{PaCO}_{2}$ during wakefulness, as well as higher pulmonary artery pressure and more hypoxemia during sleep compared to other study subjects. Recent data suggest that obstructive sleep apnea is not any more common in COPD than in the general population but that sleep-disordered breathing has a more severe course [37]. In a separate study, patients with sleep apnea had a lower 5 year mortality if they were heavy smokers or had COPD [38]. COPD patients at risk for overlap syndrome (those with polycythemia, cor pulmonale, or neuropsychological impairment) should be appropriately screened. Oximetry will show sawtoothing oxygen desaturation during NREM periods, with persistently low $\mathrm{SaO}_{2}$ during REM. Treatment with continuous positive airway pressure or bilevel positive airway pressure is indicated for patients with an overlap syndrome [39].

\section{Noninvasive Treatment Options}

Nocturnal oxygen therapy (NOT) is sometimes recommended for NOD with concomitant polycythemia or cor pulmonale. Although multiple studies have examined the use of NOT in the setting of NOD [40,41], none have demonstrated a decrease in mortality resulting from this treatment. Although risk of $\mathrm{CO}_{2}$ retention has been a clinical concern, in fact these risks have been shown to be typically modest and nonprogressive. Some small studies suggest that patients will sleep better with NOT, but the data are not highly convincing $[42,43]$.

Nocturnal positive pressure ventilation (NPPV) is the delivery of mechanically assisted breaths without placement of an artificial airway, usually with the use of a fitted nasal mask. In the setting of COPD, NPPV is more controversial than its use in the setting of neuromuscular disease as study results have been discrepant. The early interest in using NPPV for patients with severe COPD was based upon physiologic studies showing that because patients with COPD were hyperinflated, they relied upon 
accessory and parasternal muscles as opposed to the diaphragm during inspiration, which greatly increased the oxygen cost of breathing [44]. However, a meta-analysis of the medical literature [44] published about a decade ago showed that most studies of NPPV in stable COPD subjects showed minimal or no benefits in pulmonary function, gas exchange, or sleep efficiency. Respiratory muscle fatigue was not considered to be an important contributing factor in stable patients.

Several short-term studies (10-120 min) $[45,46]$ have shown some benefit. NPPV appears to decrease the inspiratory work of breathing, reduce diaphragmatic electromyogram activity, improve $\mathrm{PaO}_{2}$, decrease $\mathrm{PaCO}_{2}$, and increase minute ventilation. Overall, the level of evidence for use of NPPV is not strong (table 3). Studies suggest it works best in those with higher $\mathrm{PaCO}_{2}$, but that approximately $25 \%$ of patients will be intolerant [47]. Either volume or pressure modes are equally effective, but pressure support appears to be better tolerated and more comfortable [47].

Consensus statement guidelines for NPPV in COPD [44] indicate that conflicting results of studies hinder strong evidence-based recommendations, but nonetheless suggest some clinical strategies. Those most likely to benefit are individuals with substantial daytime $\mathrm{CO}_{2}$ retention and NOD. Indications for usage include: (a) symptoms (e.g. fatigue, dyspnea, or morning headache); (b) physiologic criteria $\left(\mathrm{PaCO}_{2} \geq 55\right.$ or $50-54 \mathrm{~mm} \mathrm{Hg}$ with NOD), or (c) $\mathrm{PaCO}_{2} 50-54 \mathrm{~mm} \mathrm{Hg}$ with recurrent hospitalization related to episodes of hypercapnic respiratory failure. Clinical considerations related to NPPV use include patient motivation and compliance, severe cognitive dysfunction, need for continuous ventilatory assistance, financial and caregiver resources, and mask fit. Patients with severe swallowing dysfunction are not good candidates for NPPV [48].

Two studies $[49,50]$ that evaluated the use of longterm oxygen therapy with or without NPPV in patients with severe COPD had discrepant results. A small study [49] of patients randomized to NPPV, oxygen therapy, or a combination of the two for 2 weeks reported no difference in sleep stages, and worse sleep efficiency with NPPV. No clinical benefits were observed. A larger, long-term study [50] comparing oxygen therapy with NPPV or a combination of both reported improved $\mathrm{PaCO}_{2}$, resting dyspnea, and health-related quality of life but no difference between treatment groups in lung function, inspiratory capacity, exercise tolerance, or sleep quality. Notably, hospital admissions and intensive care unit stays decreased dramatically in patients re-
Table 3. Levels of evidence supporting NPPV use for stable COPD (Hill [75], reproduced with permission)

\begin{tabular}{ll}
\hline Benefit & Level of evidence \\
\hline Symptoms & B \\
Ventilation & B (short-term A) \\
Sleep duration & B \\
Respiratory mm strength & A (short term) \\
Functional capacity & C \\
$\quad$ During use & A \\
After use & none \\
Hurvival & C \\
Realth status & B \\
\hline
\end{tabular}

$\mathrm{A}=$ Multiple randomized controlled trials; $\mathrm{B}=$ single randomized controlled trial; $\mathrm{C}=$ case series, cohort trials.

ceiving combination treatment (45 and $75 \%$, respectively). Treatment was not associated with increased survival, however.

\section{Drug Treatments}

Two small studies have investigated the therapeutic effects of medroxyprogesterone on oxygen desaturation. The first study of 17 subjects reported increased $\mathrm{PaO}_{2}$ and decreased $\mathrm{PaCO}_{2}$ during wake, but no significant improvement in oxygen saturation during sleep [51]. A recent placebo-controlled crossover study conducted in 13 postmenopausal women found treatment improved $\mathrm{SaO}_{2}$ and transcutaneous carbon dioxide tension during sleep. Changes were also noted in REM sleep, indicating a therapeutic response throughout the sleep cycle. Treatment effects persisted even following treatment cessation, suggestive of a hormonal therapeutic response that is worthy of additional study [52]. Conversely, studies of almitrine [53-55], a peripheral chemoreceptor agonist, have not demonstrated a significant therapeutic effect.

Studies of the effects of $\beta$-agonists on sleep in the setting of COPD demonstrate, in general, no adverse effects on sleep or nocturnal oxygenation [56, 57]. Studies of anticholinergics showed that ipratropium improved overall mean nocturnal $\mathrm{SaO}_{2}$ as well as REM time, and also demonstrated subjective improvement in sleep quality [58]. Of course, medications with longer half-lives will have greater benefit during sleep as patients will not have to awaken to re-dose in the middle of the night. Treatment 
with tiotropium improved spirometry, oxygen saturation in REM sleep, and TST with no adverse effects on sleep quality [59]. Studies of inhaled steroids used in combination suggest some treatment benefits for sleep. When fluticasone propionate with salmeterol was compared with ipratropium bromide/albuterol for the treatment of COPD, the fluticasone-salmeterol group experienced fewer nighttime awakenings, fewer sleep symptoms, and more albuterol-free nights [60]. Salmeterol alone was compared to placebo in 15 patients $(12$ completed the trial) in a randomized, placebo-controlled double-blind study for 4 weeks with salmeterol use resulting in improved mean oxygen saturation during sleep and less time at an oxygen saturation $<90 \%$, with no change in sleep quality [61]. Another randomized, placebo-controlled double-blind study of severe, stable COPD patients assessed the effects of tiotropium on $\mathrm{SaO}_{2}$ and sleep quality [59]. This study also demonstrated higher $\mathrm{SaO}_{2}$ during TST. Additionally the study reported more symptom-free nights, fewer nocturnal awakenings due to respiratory symptoms, improved sleep symptom scores, and reduced need for rescue medications. Newer longacting $\beta$-agonists, anticholinergics, and anti-inflammatory agents hold promise in further reducing nocturnal symptoms in COPD patients [62].

\section{Sleep Quality in COPD}

Like patients with any chronic disease, patients with COPD who have perceptions of poor health are likely to experience anxiety, depression, sleep disturbance, and problems with daily functioning. Research shows that approximately $40-50 \%$ of COPD patients report depression and/or anxiety [63-65]. Insomnia is one of the diagnostic criteria for major depressive disorder. Additionally, insomnia may persist even during remission and be a marker for recurrence. Further, patients who experience major depressive disorder may be more likely to be nonresponders to antidepressant therapy and experience an increased risk of suicidal behavior. Clearly, depression in COPD patients has serious health consequences, and has been linked to higher mortality in these patients [66]. Yet consensus on how to manage insomnia in COPD is lacking.

Research has demonstrated that combining eszopiclone and fluoxetine may benefit patients with major depressive disorder and insomnia. In a randomized study [67], 545 patients who received fluoxetine in the morning were randomized to eszopiclone plus fluoxetine or pla- cebo at night for 8 weeks. Patients who received combination therapy experienced significantly decreased sleep latency and wake time after sleep onset. Other benefits reported include increased TST, sleep quality, and depth of sleep at all double-blind time points (all $\mathrm{p}<0.05)$. Eszopiclone co-therapy also resulted in significantly greater changes in the Hamilton Rating Scale for Depression (HAMD-17), which improved progressively $(\mathrm{p}=0.01$ week 4 , and $p=0.002$ week 8 ), and significantly improved Clinical Global Impressions scale scores $(\mathrm{p}<0.05)$. There were also significantly more responders (59 vs. $48 \%$; $\mathrm{p}=$ 0.009 ) and remitters ( 42 vs. $33 \% ; \mathrm{p}=0.03$ ) in patients receiving combination therapy. Discontinuation rates due to adverse effects were similar between the two treatment groups.

Despite these reported benefits, many clinicians hesitate to treat insomnia in the setting of COPD out of concern that hypnotics and other medications may further impair breathing. Whereas some sedatives and narcotics such as benzodiazepines and opioids worsen oxygen desaturation during sleep and are not recommended, some newer, non-benzodiazepine hypnotics appear to be safe in patients with mild-to-moderate COPD. Zolpidem and zopiclone have both been shown to improve sleep in COPD patients, and neither drug caused significant impairment in respiratory parameters [68-70]. Similarly, a recent study showed that a melatonin agonist, ramelteon, is also safe to use in COPD patients [71]. Although some patients use alcohol as a hypnotic, patients should be advised to refrain from alcohol use, particularly in the evenings, as heavy use has been associated with increased hypoventilation and ventricular ectopy $[72,73]$.

Management of comorbid depression and/or insomnia complaints in COPD patients requires careful consideration of the effects of medications. In addition to medications, alternative nonpharmacologic treatments should also be considered, such as cognitive behavioral therapy. Clearly, this is an area that deserves further study.

\section{Conclusions}

Sleep can have profound effects on ventilation in patients with COPD, and NOD is common in this setting. Prediction of the patients who are at risk for NOD is difficult. Although treatment of NOD has not been shown to increase overall survival rates, lack of treatment has been associated with a variety of medical problems, including sustained pulmonary hypertension and in- 
creased mortality. Although in the setting of COPD clinicians are likely to ask patients about daytime drowsiness, they are unlikely to ask about insomnia and other sleep disturbances. Clinicians should consider treatment of comorbid sleep disturbances, including obstructive sleep apnea and insomnia, which may benefit the underlying COPD as well [15].

\section{Acknowledgments}

This paper is based on a presentation by Nancy Collop, MD, FCCP, at a meeting titled 'Comorbidities in COPD Taskforce', which took place in Jacksonville, Fla., USA, on March 10-11, 2008. The article was prepared with the editorial assistance of Genevieve Belfiglio, a medical writer working with Advanced Studies in Medicine, and reviewed by Dr. Bruce E. Krieger of the University of Miami, and funded by Boehringer-Ingelheim Pharmaceuticals Inc. and Pfizer Inc.

\section{References}

1 Purves D, Augustine GJ, Fitzpatrick D, Katz LC, LaMantia AS, McNamara JO, Williams SM: Neuroscience, ed 2. Sunderland, Sinauer, 2001.

2 Mohsenin V: Sleep in chronic obstructive pulmonary disease. Semin Respir Crit Care Med 2005;26:109-116.

-3 Stradling JR, Chadwick GA, Frew AJ: Changes in ventilation and its components in normal subjects during sleep. Thorax 1985;40: 364-370.

4 West JB: Respiratory Physiology: The Essentials, ed 6. Philadelphia, Lippincott Williams \& Wilkins, 2000.

5 DeMarco FJ Jr, Wynne JW, Block AJ, Boysen PG, Taasan VC: Oxygen desaturation during sleep as a determinant of the 'Blue and Bloated' syndrome. Chest 1981;79:621-625.

6 Coccagna G, Lugaresi E: Arterial blood gases and pulmonary and systemic arterial pressure during sleep in chronic obstructive pulmonary disease. Sleep 1978;1:117-124.

7 Douglas NJ, Calverley PM, Leggett RJ, Brash HM, Flenley DC, Brezinova V: Transient hypoxaemia during sleep in chronic bronchitis and emphysema. Lancet 1979;i:1-4.

8 Koo KW, Sax DS, Snider GL: Arterial blood gases and $\mathrm{pH}$ during sleep in chronic obstructive pulmonary disease. Am J Med 1975;58:663-670.

$\checkmark 9$ Wynne JW, Block AJ, Hemenway J, Hunt LA, Flick MR: Disordered breathing and oxygen desaturation during sleep in patients with chronic obstructive lung disease (COLD). Am J Med 1979;66:573-579.

10 Block AJ, Boysen PG, Wynne JW: The origins of cor pulmonale: a hypothesis. Chest 1979;75:109-110.

-11 Flenley DC: Clinical hypoxia: causes, consequences, and correction. Lancet 1978;1:542546.

12 Connaughton JJ, Catterall JR, Elton RA, Stradling JR, Douglas NJ: Do sleep studies contribute to the management of patients with severe chronic obstructive pulmonary disease? Am Rev Respir Dis 1988;138:341344.

$\$ 13$ Gay PC: Chronic obstructive pulmonary disease and sleep. Respir Care 2004;49:3951, discussion 51-52.

-14 Heijdra YF, Dekhuijzen PN, van Herwaarden CL, Folgering HT: Nocturnal saturation and respiratory muscle function in patients with chronic obstructive pulmonary disease. Thorax 1995;50:610-612.

15 Becker HF, Piper AJ, Flynn WE, McNamara SG, Grunstein RR, Peter JH, Sullivan CE: Breathing during sleep in patients with nocturnal desaturation. Am J Respir Crit Care Med 1999;159:112-118.

16 Phillipson EA: Control of breathing during sleep. Am Rev Respir Dis 1978;118:909-939.

17 Douglas NJ: Nocturnal hypoxemia in patients with chronic obstructive pulmonary disease. Clin Chest Med 1992;13:523-532.

18 Catterall JR, Calverley PM, MacNee W, Warren PM, Shapiro CM, Douglas NJ, Flenley DC: Mechanism of transient nocturnal hypoxemia in hypoxic chronic bronchitis and emphysema. J Appl Physiol 1985;59:16981703.

19 Fletcher EC, Gray BA, Levin DC: Nonapneic mechanisms of arterial oxygen desaturation during rapid-eye-movement sleep. J Appl Physiol 1983;54:632-639.

20 Ballard RD, Clover CW, Suh BY: Influence of sleep on respiratory function in emphysema. Am J Respir Crit Care Med 1995;151:945951.

21 Mulloy E, McNicholas WT: Ventilation and gas exchange during sleep and exercise in severe COPD. Chest 1996;109:387-394.

22 Chaouat A, Weitzenblum E, Kessler R, Charpentier C, Ehrhart M, Levi-Valensi P, Zielinski J, Delaunois L, Cornudella R, Moutinho dos Santos J: Sleep-related $\mathrm{O}_{2}$ desaturation and daytime pulmonary haemodynamics in COPD patients with mild hypoxaemia. Eur Respir J 1997;10:1730-1735.

-23 Campen MJ, Shimoda LA, O'Donnell CP: Acute and chronic cardiovascular effects of intermittent hypoxia in C57BL/6J mice. J Appl Physiol 2005;99:2028-2035.

24 Moore-Gillon JC, Cameron IR: Right ventricular hypertrophy and polycythaemia in rats after intermittent exposure to hypoxia. Clin Sci (Lond) 1985;69:595-599.

25 Weitzenblum E, Chaouat A: Sleep and chronic obstructive pulmonary disease. Sleep Med Rev 2004;8:281-294.

26 Lewis CA, Fergusson W, Eaton T, Zeng I, Kolbe J: Isolated nocturnal desaturation in COPD: prevalence and impact on quality of life and sleep. Thorax 2009;64:133-138.

27 Lewis CA, Eaton TE, Fergusson W, Whyte KF, Garrett JE, Kolbe J: Home overnight pulse oximetry in patients with COPD: more than one recording may be needed. Chest 2003;123:1127-1133.

28 Sanders MH, Newman AB, Haggerty CL, Redline S, Lebowitz M, Samet J, O'Connor GT, Punjabi NM, Shahar E: Sleep and sleepdisordered breathing in adults with predominantly mild obstructive airway disease. Am J Respir Crit Care Med 2003;167:7-14.

-29 Sergi M, Rizzi M, Andreoli A, Pecis M, Bruschi C, Fanfulla F: Are COPD patients with nocturnal REM sleep-related desaturations more prone to developing chronic respiratory failure requiring long-term oxygen therapy? Respiration 2002;69:117-122.

30 Catterall JR, Douglas NJ, Calverley PM, Shapiro $\mathrm{CM}$, Brezinova $\mathrm{V}$, Brash HM, Flenley DC: Transient hypoxemia during sleep in chronic obstructive pulmonary disease is not a sleep apnea syndrome. Am Rev Respir Dis 1983;128:24-29.

-31 Mulloy E, Fitzpatrick M, Bourke S, O’Regan A, McNicholas WT: Oxygen desaturation during sleep and exercise in patients with severe chronic obstructive pulmonary disease. Respir Med 1995;89:193-198.

- 32 McKeon JL, Murree-Allen K, Saunders NA: Prediction of oxygenation during sleep in patients with chronic obstructive lung disease. Thorax 1988;43:312-317.

33 Little SA, Elkholy MM, Chalmers GW, Farouk A, Patel KR, Thomson NC: Predictors of nocturnal oxygen desaturation in patients with COPD. Respir Med 1999;93:202-207.

-34 Zanchet RC, Viegas CA: Nocturnal desaturation: predictors and the effect on sleep patterns in patients with chronic obstructive pulmonary disease and concomitant mild daytime hypoxemia. J Bras Pneumol 2006; 32:207-212.

35 Flenley DC: Sleep in chronic obstructive lung disease. Clin Chest Med 1985;6:651661.

36 Chaouat A, Weitzenblum E, Krieger J, Ifoundza T, Oswald M, Kessler R: Association of chronic obstructive pulmonary disease and sleep apnea syndrome. Am J Respir Crit Care Med 1995;151:82-86.

37 Bednarek M, Plywaczewski R, Jonczak L, Zielinski J: There is no relationship between chronic obstructive pulmonary disease and obstructive sleep apnea syndrome: a population study. Respiration 2005;72:142-149. 
- 38 Chaouat A, Weitzenblum E, Krieger J, Sforza E, Hammad H, Oswald M, Kessler R: Prognostic value of lung function and pulmonary haemodynamics in OSA patients treated with CPAP. Eur Respir J 1999;13:1091-1096.

39 Mansfield D, Naughton MT: Effects of continuous positive airway pressure on lung function in patients with chronic obstructive pulmonary disease and sleep disordered breathing. Respirology 1999;4:365-370.

40 Continuous or nocturnal oxygen therapy in hypoxemic chronic obstructive lung disease: a clinical trial. Nocturnal Oxygen Therapy Trial Group. Ann Intern Med 1980;93:391398.

41 Folgering H: Supplemental oxygen for COPD patients with nocturnal desaturations? Eur Respir J 1999;14:997-999.

-42 Calverley PM, Brezinova V, Douglas NJ, Catterall JR, Flenley DC: The effect of oxygenation on sleep quality in chronic bronchitis and emphysema. Am Rev Respir Dis 1982; 126:206-210

43 Goldstein RS, Ramcharan V, Bowes G, McNicholas WT, Bradley D, Phillipson EA: Effect of supplemental nocturnal oxygen on gas exchange in patients with severe obstructive lung disease. N Engl J Med 1984;310: 425-429.

44 Clinical indications for noninvasive positive pressure ventilation in chronic respiratory failure due to restrictive lung disease, COPD, and nocturnal hypoventilation - a consensus conference report. Chest 1999;116:521534.

-45 Girault C, Richard JC, Chevron V, Tamion F, Pasquis P, Leroy J, Bonmarchand G: Comparative physiologic effects of noninvasive assist-control and pressure support ventilation in acute hypercapnic respiratory failure. Chest 1997;111:1639-1648.

46 Goldstein RS, De Rosie JA, Avendano MA, Dolmage TE: Influence of noninvasive positive pressure ventilation on inspiratory muscles. Chest 1991;99:408-415.

-47 Windisch W, Storre JH, Sorichter S, Virchow JC Jr: Comparison of volume- and pressurelimited NPPV at night: a prospective randomized cross-over trial. Respir Med 2005; 99:52-59.

48 Hill NS: Noninvasive ventilation for chronic obstructive pulmonary disease. Respir Care 2004;49:72-87, discussion 87-89.

49 Lin CC: Comparison between nocturnal nasal positive pressure ventilation combined with oxygen therapy and oxygen monotherapy in patients with severe COPD. Am I Respir Crit Care Med 1996;154:353-358.

-50 Clini E, Sturani C, Rossi A, Viaggi S, Corrado A, Donner CF, Ambrosino N: The Italian multicentre study on noninvasive ventilation in chronic obstructive pulmonary disease patients. Eur Respir J 2002;20:529538.
Dolly FR, Block AJ: Medroxyprogesterone acetate and COPD. Effect on breathing and oxygenation in sleeping and awake patients. Chest 1983;84:394-398.

52 Saaresranta T, Aittokallio T, Utriainen K, Polo O: Medroxyprogesterone improves nocturnal breathing in postmenopausal women with chronic obstructive pulmonary disease. Respir Res 2005;6:28.

53 Daskalopoulou E, Patakas D, Tsara V, Kazis A, Maniki E, Zoglopitis F: Almitrine effect on nocturnal hypoxaemia in patients with chronic obstructive pulmonary disease (COPD). Bull Eur Physiopathol Respir 1987; 23(suppl 11):185s-190s.

4 Gothe B, Cherniack NS, Bachand RT Jr, Szalkowski MB, Bianco KA: Long-term effects of almitrine bismesylate on oxygenation during wakefulness and sleep in chronic obstructive pulmonary disease. Am J Med 1988;84:436-444.

55 Sans-Torres J, Domingo C, Moron A, Rue M, Marin A: Long-term effects of almitrine bismesylate in COPD patients with chronic hypoxaemia. Respir Med 2003;97:599-605.

56 Veale D, Cooper BG, Griffiths CJ, Corris PA, Gibson GJ: The effect of controlled-release salbutamol on sleep and nocturnal oxygenation in patients with asthma and chronic obstructive pulmonary disease. Respir Med 1994;88:121-124.

57 Campbell M, Eliraz A, Johansson G, Tornling G, Nihlen U, Bengtsson T, Rabe KF: Formoterol for maintenance and as-needed treatment of chronic obstructive pulmonary disease. Respir Med 2005;99:1511-1520.

58 Martin RJ, Bartelson BL, Smith P, Hudgel DW, Lewis D, Pohl G, Koker P, Souhrada JF: Effect of ipratropium bromide treatment on oxygen saturation and sleep quality in COPD. Chest 1999;115:1338-1345.

59 McNicholas WT, Calverley PM, Lee A, Edwards JC: Long-acting inhaled anticholinergic therapy improves sleeping oxygen saturation in COPD. Eur Respir J 2004;23: 825-831.

60 Donohue JF, Kalberg C, Emmett A, Merchant K, Knobil K: A short-term comparison of fluticasone propionate/salmeterol with ipratropium bromide/albuterol for the treatment of COPD. Treat Respir Med 2004;3: 173-181.

61 Ryan S, Doherty LS, Rock C, Nolan GM, McNicholas WT: Effects of salmeterol on sleeping oxygen saturation in chronic obstructive pulmonary disease. Respiration 2010;79: 475-481.

62 Molfino NA: Drugs in clinical development for chronic obstructive pulmonary disease. Respiration 2005;72:105-112.

63 Cully JA, Graham DP, Stanley MA, Ferguson CJ, Sharafkhaneh A, Souchek J, Kunik ME: Quality of life in patients with chronic obstructive pulmonary disease and comorbid anxiety or depression. Psychosomatics 2006; 47:312-319.
64 Karajgi B, Rifkin A, Doddi S, Kolli R: The prevalence of anxiety disorders in patients with chronic obstructive pulmonary disease. Am J Psychiatry 1990;147:200-201.

65 Yohannes AM, Baldwin RC, Connolly MJ Depression and anxiety in elderly outpatients with chronic obstructive pulmonary disease: prevalence, and validation of the BASDEC screening questionnaire. Int Geriatr Psychiatry 2000;15:1090-1096.

-66 Ng TP, Niti M, Tan WC, Cao Z, Ong KC, Eng P: Depressive symptoms and chronic obstructive pulmonary disease: effect on mortality, hospital readmission, symptom burden, functional status, and quality of life. Arch Intern Med 2007;167:60-67.

67 Fava M, McCall WV, Krystal A, Wessel T, Rubens R, Caron J, Amato D, Roth T: Eszopiclone co-administered with fluoxetine in patients with insomnia coexisting with major depressive disorder. Biol Psychiatry 2006; 59:1052-1060

68 Girault C, Muir JF, Mihaltan F, Borderies P, De La Giclais B, Verdure A, Samson-Dollfus D: Effects of repeated administration of zolpidem on sleep, diurnal and nocturnal respiratory function, vigilance, and physical performance in patients with COPD. Chest 1996;110:1203-1211.

-69 Steens RD, Pouliot Z, Millar TW, Kryger $\mathrm{MH}$, George CF: Effects of zolpidem and triazolam on sleep and respiration in mild to moderate chronic obstructive pulmonary disease. Sleep 1993;16:318-326.

70 Muir JF, DeFouilloy C, Broussier P, Locquet R, Maillard F: Comparative study of the effects of zopiclone and placebo on respiratory function in patients with chronic obstructive respiratory insufficiency. Int Clin Psychopharmacol 1990;5(suppl 2):85-94.

-71 Kryger M, Wang-Weigand S, Zhang J, Roth T: Effect of ramelteon, a selective MT(1)/ MT(2)-receptor agonist, on respiration during sleep in mild to moderate COPD. Sleep Breath 2008;12:243-250.

72 Dolly FR, Block AJ: Increased ventricular ectopy and sleep apnea following ethanol ingestion in COPD patients. Chest 1983;83: 469-472.

73 Easton PA, West P, Meatherall RC, Brewster JF, Lertzman M, Kryger MH: The effect of excessive ethanol ingestion on sleep in severe chronic obstructive pulmonary disease. Sleep 1987;10:224-233.

74 Collop NA, Salas RE, Delayo M, Gamaldo C: Normal sleep and circadian processes. Crit Care Clin 2008;24:449-460.

75 Hill NS: Noninvasive ventilation in chronic obstructive pulmonary disease. Clin Chest Med 2000;21:783-797.

76 Parmeggiani PL: Physiologic regulation in sleep; in Kryger MH, Roth T, Dement WC (eds): Principles and Practice of Sleep Medicine, ed 4. Philadelphia, Elsevier Health Sciences, 2005. 